\title{
A General Strategy to the Intracellular Sensing of Glycosidases using AIE-Based Glycoclusters
}

Lei Dong, ${ }^{\mathrm{a}, \mathrm{b}, \star}$ Min-Yu Zhang, ${ }^{\mathrm{a},}$ Hai-Hao Han, ${ }^{\mathrm{a}, \$}$ Yi Zang, ${ }^{\mathrm{c}}$ Guo-Rong Chen, ${ }^{\mathrm{a}} \mathrm{Jia} \mathrm{Li},{ }^{\mathrm{c}, *}$ XiaoPeng He, ${ }^{\mathrm{a}, *}$ and Sébastien Vidal ${ }^{\mathrm{b}, \mathrm{d}, *}$

${ }^{a}$ Key Laboratory for Advanced Materials and Joint International Research Laboratory of Precision Chemistry and Molecular Engineering, Feringa Nobel Prize Scientist Joint Research Center, Frontiers Center for Materiobiology and Dynamic Chemistry, School of Chemistry and Molecular Engineering, East China University of Science and Technology, 130 Meilong Rd., Shanghai 200237, P.R. China.

${ }^{\mathrm{b}}$ Institut de Chimie et Biochimie Moléculaires et Supramoléculaires, Laboratoire de Chimie Organique 2-Glycochimie, UMR 5246, CNRS and Université Claude Bernard Lyon 1, Université de Lyon, 1 Rue Victor Grignard, F-69622 Villeurbanne, France.

${ }^{\mathrm{c}}$ National Centre for Drug Screening, State Key Laboratory of Drug Research, Shanghai Institute of Materia Medica, Chinese Academy of Sciences, 189 Guo Shoujing Rd., Shanghai 201203, PR China.

${ }^{\mathrm{d} U n i v e r s i t e ́ ~ P a r i s-S a c l a y, ~ C N R S, ~ I n s t i t u t ~ d e ~ C h i m i e ~ d e s ~ S u b s t a n c e s ~ N a t u r e l l e s, ~ U P R ~ 2301, ~}$ 91198, Gif-sur-Yvette, France.

*Corresponding authors: sebastien.vidal@cnrs.fr; xphe@ecust.edu.cn; jli@simm.ac.cn 


\section{Abstract}

Glycosidases, which are the enzymes responsible for removal of residual monosaccharides from glycoconjugates, are implicated in a myriad of biological and pathological events. The ability to detect sensitively the activity and spatiotemporal distribution of glycosidases in cells may facilitate the study of glycobiology, and add useful diagnostic tools. However, the currently developed fluorogenic probes for glycosidases are generally based on glycosylation of a phenol group of a donor-acceptor type fluorogen. This general molecular scaffold has potential drawbacks in terms of substrate scope, sensitivity because of aggregation-caused quenching (ACQ), and the inability for long-term cell tracking. Here, we developed glycoclusters characterized by aggregation-induced emission (AIE) properties as a general platform for the sensing of a variety of glycosidases. To overcome the low chemical reactivity during phenol glycosylation, we synthesized an AIE-based dye composed of tetraphenylethylene conjugated with dicyanomethylene-4H-pyran (TPE-DCM) with a red fluorescence emission. Subsequently, a pair of dendritic linkages was introduced to both sides of the fluorophore, to which six copies of different monosaccharides (D-glucose, D-galactose and L-fucose) were conjugated through azide-alkyne click chemistry. The resulting AIE-active glycoclusters were shown to be capable of (1) fluorogenic sensing of a diverse range of glycosidases including $\beta$-D-galactosidase, $\beta$-D-glucosidase and $\alpha$-L-fucosidase through the AIE mechanism, (2) fluorescence imaging of the endogenous glycosidase activities in healthy and cancer cells, and during cell senescence, and (3) glycosidase-activated, long-term imaging of cells. The present study provides a general strategy to the functional imaging of glycosidase activities through the multivalent display of sugar epitopes of interest onto AIE-active dyes. 


\section{Introduction}

Glycosidases play a critical role in many biological processes through the hydrolysis of di- or polysaccharides from glycoconjugates. ${ }^{1}$ Among them, $\beta$-D-galactosidase ( $\beta$-Gal) is an essential enzyme involved in monitoring the efficiency of transcription and transfection of genes, and has also been demonstrated as a key biomarker for cell senescence, cell growth, gene expression, ovarian cancer and other pathological processes..$^{2-4} \alpha$-Fucosidase (AFU) is commonly found in mammalian cells, which hydrolyzes the L-fucosyl residue from glycoconjugates at an acidic $\mathrm{pH}(\mathrm{pH} 4$ to 6.5$)$. AFU is involved in many biological processes such as inflammation, growth regulation, ligand-receptor recognition, antigenicity, and is also implicated in human diseases including fucosidosis ${ }^{5}$ and carcinoma ${ }^{6-8}$ Therefore, the ability to accurately monitor the activity of endogenous glycosidases is of prime importance for the basic study of glycobiology as well as for disease diagnosis.

Compared to the traditional colorimetric biochemical tests and the enzyme-linked immunosorbent assay, fluorescent probes have been viewed as a more privileged technique for the detection of enzymatic activities due to their high sensitivity, simplicity in design and preparation, and the ability for the in-situ imaging of enzymatic activities in cells and in vivo. ${ }^{9-}$ ${ }^{14}$ The rationale by which glycosidase probes are designed typically relied on the conjugation of one molecule of monosaccharide to the phenol group of a donor-acceptor (D-A) type fluorogen (Table S1). This glycosylation quenches the intrinsic fluorescence of the phenol dye through modulation of the intramolecular charge transfer (ICT) or photo-induced electronic transfer (PeT) process. ${ }^{15-18}$ Subsequently, hydrolysis of the glycosyl group from the dye by a selective glycosidase causes the fluorescence to recover (fluorescence off-on) (Figure 1a). A 
number of fluorogenic glycosidase probes has been developed based on this strategy with good sensitivity and selectivity. ${ }^{18-21}$ To minimize background bioluminescence and light scattering, the phenol glycosylation strategy has been extended to near-infrared (NIR) dyes for the monitoring of glycosidase activities in vivo. ${ }^{22-28}$ However, the previously used dyes for glycosidase detection generally suffer from aggregation-caused quenching (ACQ) in aqueous media, and are easily bound unselectively to biomacromolecules leading to possible falsepositive signals.

a

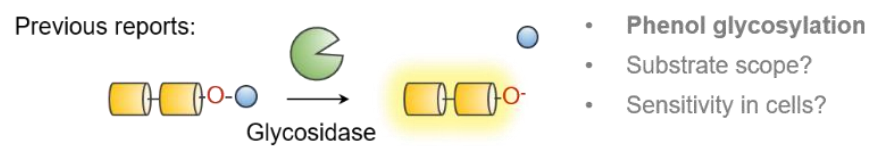

This work:

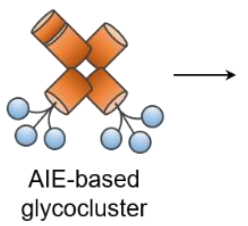

Dendritic "click" ligation

Substrate scope $\sqrt{ }$

Long-term cell tracking $\sqrt{ }$

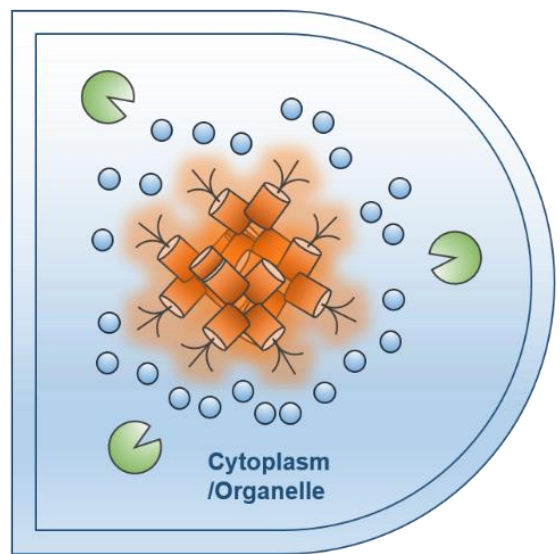

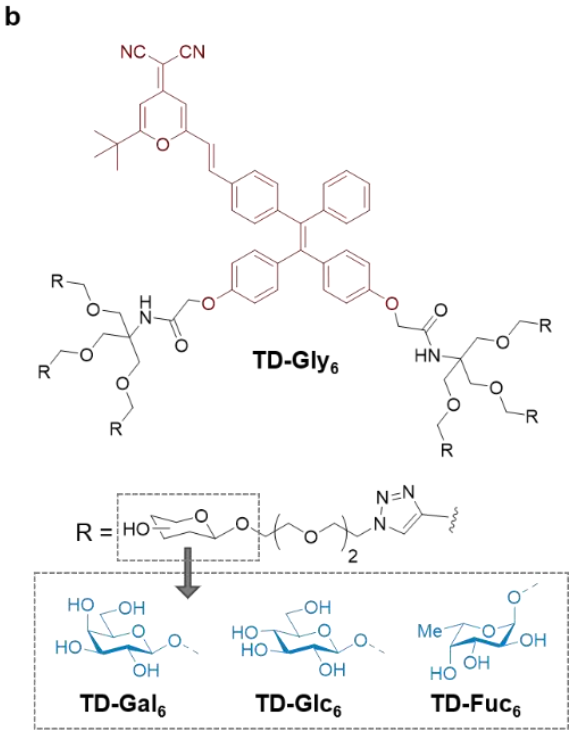

Figure 1. (a) Previously reported glycosidase-activated probes based on phenol glycosylation and the development of AIE-based glycoclusters (this work) as a general platform for the detection of a wider range of glycosidases, enabling the long-term, glycosidase-activated fluorescence tracking of cells. (b) Structure of the AIE glycoclusters synthesized in this study including AIE-based galactosyl cluster TD-Gal, glucosyl cluster TD-Glc6, and fucosyl cluster TD-Fuc6.

In 2001, Tang's group coined the concept of aggregation-induced emission (AIE) ${ }^{29}$ Since then, a number of AIE-based fluorophores have been developed. ${ }^{17,30-34}$ AIE-based probes have 
also been used for the fluorescence imaging of intracellular enzymes ${ }^{14}$ including glycosidases through the introduction of monosaccharides to AIEgens. ${ }^{17,26,35}$ The fluorescence of the AIEbased probes is significantly enhanced upon removal of the glycosyl group from the AIEgen leading to molecular aggregation. Meanwhile, nanoaggregates that are composed of selfassembled AIEgens have also been developed, leading to a slower rate of exocytosis than soluble small molecules. This allows one to monitor intracellular glycosidase activities in a long-term manner. ${ }^{36-37}$ However, previously reported probes are generally limited to the detection of a single glycosidase such as $\beta-G a l .{ }^{38}$ This is mainly due to the difficulty in glycosylation of phenolic alcohols with other hexoses. ${ }^{39-43}$ In particular, L-fucose as a 6-deoxy sugar is more electron rich than its parent hexose hence more prone to hydrolysis of its glycosidic bond. ${ }^{44-45}$ As a consequence, a new platform strategy for visualizing a more diverse range of glycosidases implicated in the myriad of biologically and pathologically important cellular events is highly needed.

Here, we develop an AIE-based glycocluster strategy for the fluorogenic sensing and longterm cell imaging of a diverse range of glycosidases. We have previously developed a D-Atype AIEgen based on a TPE core conjugated with a DCM derivative (TPE-DCM or TD) with a reddish fluorescence emission $\left(\lambda_{\max }^{e m}=625 \mathrm{~nm}\right) \cdot{ }^{46-47} \mathrm{TPE}$ and DCM were conjugated to each other through an ethylene bridge to increase the delocalization of electrons in the system. Unlike previous reports that directly glycosylate phenol groups of conjugated dyes, we introduced a pair of dendritic arms on both phenol moieties of TPE (Fig. 1a). This enables the grafting of six copies of glycosyl epitopes pre-functionalized with an azido-triethyleneglycol to the fluorophore through azide-alkyne click chemistry (Fig. 1b). By comparison to a number 
of other synthetic glycoclusters bearing different linkages between the glycoside and the dye, the dendritic strategy has proven to be the most effective yielding a sensitive fluorogenic response to glycosidases. The AIE-based glycoclusters were successfully used for (1) the fluorogenic detection of functionally diverse glycosidases including galactosidase, glucosidase and fucosidase, (2) the fluorescence imaging of the endogenous glycosidase activities in healthy and cancer cells, and during cell senescence, and (3) glycosidase-activated, long-term imaging of healthy and cancer cells.

\section{RESULTS AND DISCUSSION}

Synthesis and structure-activity relationship of TPE-DCM-based glycoclusters. Four series of TPD-DCM-based glycoclusters with different linking patterns between TPE-DCM and monosaccharides were designed and synthesized; D-galactose was preliminarily used as a model saccharide ${ }^{48-50}$. The galactosyl groups were introduced to the dye by direct phenol glycosylation (linker free) (TD-Gal2) or azide-alkyne click chemistry conjugation through structurally different linker arms (short-arm, propyl: TD-CGal2, long-arm, triethyleneglycol: TD-EGGal2; dendritic-arm: TD-Gal6) (Scheme S1). The linker-free glycocluster TD-Gal2 was synthesized from intermediate 7 . The known TPE-aldehyde $5^{48}$ was coupled to DCM $\mathbf{6}^{51}$ through aldolization/crotonization. The resultant conjugate 7 with a red fluorescence emission showed a gradual fluorescence enhancement with increasing water fraction in THF (Fig. S1), which is characteristic of AIE. ${ }^{52}$ Demethylation of 7 with $\mathrm{BBr}_{3}$ in $\mathrm{CH}_{2} \mathrm{Cl}_{2}$ afforded the bisphenolic 8. Subsequently, glycosylation under phase transfer conditions with bromo tetra-Oacetyl-D-galactose afforded the desired bis-glycosylated derivative 9. As expected, this bis- 
phenol glycosylation led to a poor yield of $20 \%$; the stereoselectivity of the glycosylation was verified by analysis of the ${ }^{1} \mathrm{H}$ NMR spectrum of the compound, suggesting a $\beta$-anomeric configuration $\left(J_{1,2}=8.2 \mathrm{~Hz}\right)$. Solvolysis of the acetyl protecting groups afforded the desired glycocluster TD-Gal2.
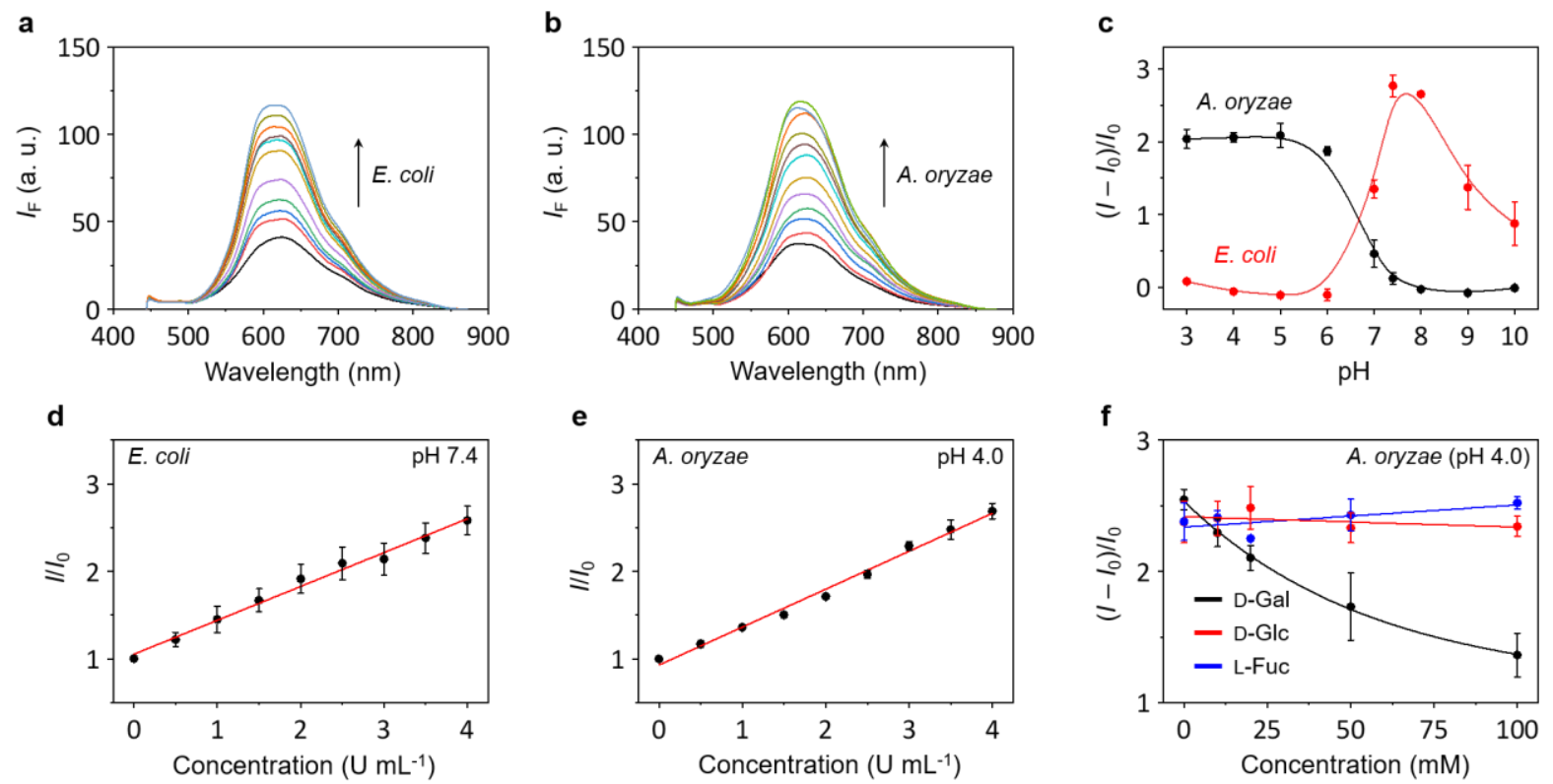

Figure 2. Fluorescence emission spectra of TD-Gal $6(10 \mu \mathrm{M})$ with (a) increasing $\beta$-Gal (0-7 U $\left.\mathrm{mL}^{-1}\right)$ purified from $E$. coli at $\mathrm{pH} 7.4$, and (b) $\beta$-Gal $\left(0-7 \mathrm{U} \mathrm{mL}^{-1}\right)$ purified from A. oryzae. at $\mathrm{pH}$ 4.0. (c) Plotting the fluorescence changes of TD-Gal6 $(10 \mu \mathrm{M})$ in the presence of $\beta$-Gal (5 $\left.\mathrm{U} \mathrm{mL}^{-1}\right)$ purified from $E$. coli and that $\left(5 \mathrm{U} \mathrm{mL}^{-1}\right)$ purified from $A$. oryzae as a function of $\mathrm{pH}$. Plotting the fluorescence changes of TD-Gal $6(10 \mu \mathrm{M})$ as a function of $(\mathrm{d})$ increasing $\beta$-Gal (0-4 $\mathrm{U} \mathrm{mL}^{-1}$; interval: $\left.0.5 \mathrm{U} \mathrm{mL}^{-1}\right)$ purified from E. coli at $\mathrm{pH} 7.4$, and (e) increasing $\beta$-Gal (0$4 \mathrm{U} \mathrm{mL}^{-1}$; interval: $0.5 \mathrm{U} \mathrm{mL}^{-1}$ ) purified from A. oryzae at $\mathrm{pH} 4.0$. (f) Plotting the fluorescence changes of TD-Gal6 $(10 \mu \mathrm{M})$ with $\beta$-Gal $\left(5 \mathrm{U} \mathrm{mL}^{-1}\right)$ purified from $A$. oryzae at $\mathrm{pH} 4.0$ as a function of increasing free D-Gal, D-Glc and L-Fuc. $I$ and $I_{0}$ are the fluorescence intensity of TD-Gal6 in the presence and absence of an analyte, respectively. All fluorescence spectra were recorded in PBS (0.01 M, pH as indicated) with an excitation at $420 \mathrm{~nm}$.

With TD-Gal2 in hand, we tested its fluorescence response to $\beta$-Gal (derived from $E$. coli. $)^{53}$ in phosphate buffered saline (PBS) at pH 7.4 (Fig. S2a). At a physiological pH (7.4), 
the fluorescence of the probe decreased in the presence of $\beta$-Gal. However, we observed that the fluorescence of TD-Gal $\mathbf{2}$ alone increased with time in PBS (pH 7.4) in the absence of the enzyme. This suggests that (a) the initial fluorescence emission intensity of the probe in PBS was unstable due to a slow rate of molecular aggregation, and, thus AIE-based fluorescence enhancement, and (2) the two galactosyl residues modified on the phenol groups did not sufficiently quench the fluorescence of the AIEgen.

With the traditional phenol glycosylation strategy being unsatisfactory, we then sought to enhance the intrinsic AIE property of TPE-DCM through improving the water solubility of the glycoclusters. The better water solubility of the glycoclusters might lead to a lowered initial fluorescence emission of the system. When the glycosyl groups are removed from the dye, the decreased water solubility of TPE-DCM could lead to a drastically enhanced emission through AIE (Figure 1a). To achieve this goal, additional linker arms (propyl, triethyleneglycol or dendritic) were introduced to TPE-DCM between the phenolic AIEgen and the galactosyl epitope. The linker arms are retained on the dye scaffold even after hydrolysis of the glycosyl groups, thereby facilitating the formation of TPE-DCM-based micelles to enhance the AIE fluorescence.

The $\mathrm{Cu}(\mathrm{I})$-catalyzed azide-alkyne cycloaddition (CuAAC) “click" chemistry was used for conjugation between the dye and monosaccharides. ${ }^{54-56}$ Starting from compound $\mathbf{8}$, propargylation was first attempted using potassium carbonate with propargyl bromide, which led to a poor chemical yield $(<15 \%)$. Addition of $\mathrm{Bu}_{4} \mathrm{NI}$ and 18 -crown- 6 enhanced the reactivity of phenolates for a proper etherification in $92 \%$ yield to obtain the bis-propargyl compound $\mathbf{1 0}$ (Scheme 1). Galactosides with a 3 -azidopropyl ${ }^{57}$ (short-arm) or azido-triethyleneglycol ${ }^{58}$ 
(long-arm) aglycon were then conjugated to compound $\mathbf{1 0}$ in the presence of $\mathrm{CuSO}_{4} /$ sodium ascorbate $(\mathrm{VcNa})$ as catalyst. ${ }^{46,59}$ Solvolysis of the ester protecting groups afforded the TDCGal2 and TD-EGGal2 probes from compound 11 and 12, respectively. The fluorescence of 11 and 12 was then measured without $\beta$-Gal in PBS buffer at pH 7.4 (Fig. S2b and c). Both glycoclusters showed a strong fluorescence emission, suggesting that the amphiphilic molecules are partially aggregated before reacting with the enzyme. Upon addition of the enzyme, the fluorescence of both probes decreased slightly. This might be the result of the formation of a poorly water-soluble AIE species after the enzymatic hydrolysis. These results suggest that the conjugation of only two glycosides onto the AIEgen is insufficient to substantially enhanced the water solubility of the dye.

We then sought the possibility of introducing more than two glycosyl groups to the phenolic positions of the AIEgen in order to substantially enhance the water solubility, achieving an optimal "off-on" fluorescence response upon incubation with glycosidases. As a consequence, a trivalent dendron was used to incorporate three glycosyl residues with each phenol group of TPE-DCM. Tris(hydroxymethyl)aminomethane (Tris) was converted into the tris-propargylated precursor 3 by a sequential synthetic route including Boc-protection, propargylation, removal of the Boc-carbamate and 2-bromo-acetamidation (Scheme S1). 2Bromo-acetamide 3 was then conjugated to the TPE-DCM bis-phenol $\mathbf{8}$ to afford the hexakispropargylated compound $\mathbf{1 3}$. CuAAC coupling of $\mathbf{1 3}$ with azido-triethyleneglycol galactoside was achieved under microwave activation to maximize the reactivity and completeness of the reaction. ${ }^{60-61}$ Removal of the protecting groups afforded the water-soluble hexavalent glycocluster TD-Gal6. The same synthetic strategy was also applied to the synthesis of the 
hexavalent glucosylated probe TD-Glc 6 and fucosylated probe TD-Fuc 6 (Scheme S1).

Subsequently, a comparative study of the AIE properties of TD-EGGal2, TD-Gal6, TDGlc6 and TD-Fuc6 $(10 \mu \mathrm{M})$ in a mixture solvent system of THF/PBS at different ratios (pH 7.4) was carried out (Fig. S3). TD-EGGal2 displayed a typical fluorescence enhancement upon increase of PBS ratio in the solvent mixture (Fig. S3a). This observation suggests that the presence of only two glycosides is not sufficient for TD-EGGal2 to remain well dispersible in water. In contrast, the fluorescence intensity of the hexakis-glycosylated probe TD-Gal6 in THF decreased with PBS (Fig. S3b). The well quenched fluorescence of the probe in full PBS suggests that TD-Gal6 was hardly aggregated in aqueous solution. Other hexakis-glycosylated probes, TD-Glc 6 (Fig. S3c) and TD-Fuc $($ Fig. S3d), showed a similar trend of fluorescence quenching with PBS ratio being increased. These results suggest that the designed hexakisglycosylated TD-Gly6 glycoclusters are sufficiently water-soluble, making possible the AIEbased detection of glycosidases.

Glycosidase sensing with the AIE-based hexavalent glycoclusters. With the TPE-DCMbased hexavalent glycoclusters (TD-Gly6) in hand, we then tested their fluorescence responses to glycosidases in PBS. TD-Gal6 with six galactosyl epitopes was first used for the detection of $\beta$-Gal purified from different bacteria. The $\beta$-Gal isolated from Escherichia coli $(\beta-\mathrm{Gal} / E$. coli) has been extensively used for analysis of the sensing performances of fluorogenic $\beta$-Gal probes. ${ }^{28}$ However, the working $\mathrm{pH}$ of this enzyme is limited to $6.5-7.5 .{ }^{53}$ Alternatively, Gao et al. proposed the use of $\beta-\mathrm{Gal}$ isolated from Aspergillus oryzae ( $\beta-\mathrm{Gal} /$ A. oryzae) with a working $\mathrm{pH}$ range (4.0-5.0) more similar to that expressed in human cells. ${ }^{62-63}$ As a result, we attempted 
the detection of the $\beta$-Gal isolated from both bacteria in order to examine the sensitivity of the AIE-based glycoclusters developed. TD-Gal6 was incubated separately with $\beta$-Gal/E. coli (pH 7.4) (Fig. 2a) and $\beta$-Gal/A. oryzae (pH 4.0) (Fig. 2b). We observed a concentration-dependent fluorescence enhancement of the probe for both galactosidases at their optimal $\mathrm{pH}$. A good linearity was observed by plotting the fluorescence enhancement of TD-Gal6 as a function of the concentration (0-4.0 $\left.\mathrm{U} \mathrm{mL}^{-1}\right)$ of $\beta-\mathrm{Gal} / E$. coli (Fig. $2 \mathrm{~d}$ ) and $\beta-\mathrm{Gal} /$ A. oryzae (Fig. 2e) at $\mathrm{pH}$ 7.4 and 4.0, respectively. The limit of detection of the probe for $\beta-\mathrm{Gal} / E$. coli and $\beta-\mathrm{Gal} / A$. oryzae was determined to be $0.015 \mathrm{U} \mathrm{mL}^{-1}$ and $0.014 \mathrm{U} \mathrm{mL}^{-1}$, respectively. Comparing to previously reported fluorogenic probe, TD-Galo is among the most sensitive for $\beta$-Gal, and its unique structural feature of possessing multiple glycosyl epitopes endows the glycocluster with a better water solubility and potentially good biocompatibility for biological assays (Table S1). In addition, we also determined that the AIE-based fluorescence enhancement is dependent on the working $\mathrm{pH}$ range of both enzymes (Fig. 2c). Within an acidic $\mathrm{pH}$ range (3-6), TD-Gal6 responded stably to $\beta-\mathrm{Gal} / A$. oryzae, whereas the fluorescence of the probe only enhanced significantly at a relatively neutral-basic $\mathrm{pH}(7-9)$ for $\beta-\mathrm{Gal} / E$. coli. This suggests that the AIEbased glycocluster probe can differentiate the working $\mathrm{pH}$ of homogeneous glycosidases derived from different bacteria.

Next, the sensing properties of TD-Gal 6 was tested in more detail. In the presence of $\beta$ $\mathrm{Gal} / E$. coli, the fluorescence $\left(\Phi_{\mathrm{F}}=0.005\right)$ of TD-Gal6 enhanced by $c a$. 5 -fold $\left(\Phi_{\mathrm{F}}=0.026\right)$ at pH 7.4 (Fig. S4). Similarly, a drastic fluorescence enhancement of 4.5 -fold ( $\Phi_{\mathrm{F}}$ from 0.006 to 0.027) was observed for the glycocluster with $\beta$-Gal/A. oryzae at $\mathrm{pH} 4.0$ (Fig. S5). This suggests that the cleavage of the glycosidic bonds in the probe by the enzyme reduced the hydrophilicity 
of the fluorescent dye, thereby leading to molecular aggregation. This action allowed for the detection of $\beta$-Gal through AIE effect in full PBS solution without the need for any organic solvent being added. To study the sensing mechanism of TD-Gal6 for $\beta$-Gal, dynamic light scattering (DLS) was used to determine the change in size of the molecular aggregates of TDGal6 in PBS solution before and after treatment with $\beta$-Gal (Fig. S6). The hydrodynamic diameter of the probe alone was determined to be $254 \mathrm{~nm}$ in PBS buffer. This observation is in agreement with the probe being at the mono-dispersed and/or a slightly aggregated state. After addition of $\beta-\mathrm{Gal} / E$. coli at $\mathrm{pH} 7.4$, the galactosyl groups on the probe are hydrolyzed to reduce the water-solubility of the dye, thereby producing more aggregated species with a particle size of $375 \mathrm{~nm}$. A competition assay was also carried out. Pre-treatment of $\beta-G a l / A$. oryzae (pH 4.0) (Fig. 2f) and $\beta$-Gal/E. coli (pH 7.4) (Fig. S7a) with free D-galactose (as $\beta$-Gal inhibitor) led to the concentration-dependent fluorescence suppression of TD-Gal6. In contrast, the pretreatment of D-glucose and L-fucose did not cause the fluorescence of the probe to decrease in the presence of $\beta-\mathrm{Gal} / A$. oryzae or $\beta-\mathrm{Gal} / E$. coli. These data suggest that the enzymatic sensing was achieved by TD-Gal6 being selectively hydrolyzed by a galactosidase, leading to molecular aggregation with an enhanced fluorescence.

Next, we tested the fluorescence response of other hexavalent glycoclusters to their corresponding glycosidase. We observed a significant fluorescence enhancement of TD-Glc 6 and TD-Fuc6 with a $\beta$-D-glucosidase $\left(\beta\right.$-Glc) ${ }^{64}$ and an $\alpha$-L-fucosidase (AFU), ${ }^{12}$ respectively (Fig. S8). By incubation of $\beta$-Glc $\left(10 \mathrm{U} \mathrm{mL}^{-1}\right)$ with TD-Gle 6 for $2.5 \mathrm{~h}$, a fluorescence enhancement of 3.7-fold ( $\Phi_{\mathrm{F}}$ from 0.010 to 0.037 ) was achieved (Fig. S8a). A good linearity was produced by plotting the fluorescence enhancement of TD-GIc 6 as a function of increasing 
$\beta$-Glc from 0 to $2 \mathrm{U} \mathrm{mL}^{-1}$ (Fig. S9a), and a LOD of $0.01 \mathrm{U} \mathrm{mL}^{-1}$ was determined $(3 \delta / \mathrm{k}$, Fig. $\mathrm{S} 9 \mathrm{~b})$. This is lower than the previously reported glucosidase probes. ${ }^{64}$ Similarly, TD-Fuc6 displayed a fluorescence increase (1.6-fold, $\Phi_{\mathrm{F}}$ from 0.006 to 0.0096$)$ after incubation with AFU (0.12 $\left.\mathrm{U} \mathrm{mL}^{-1}\right)$ (Fig. 8b). Meanwhile, the emission intensity of TD-Fuc 6 enhanced gradually with an increase of AFU concentration from 0 to $0.12 \mathrm{U} \mathrm{mL}^{-1}$ (Fig. S10).
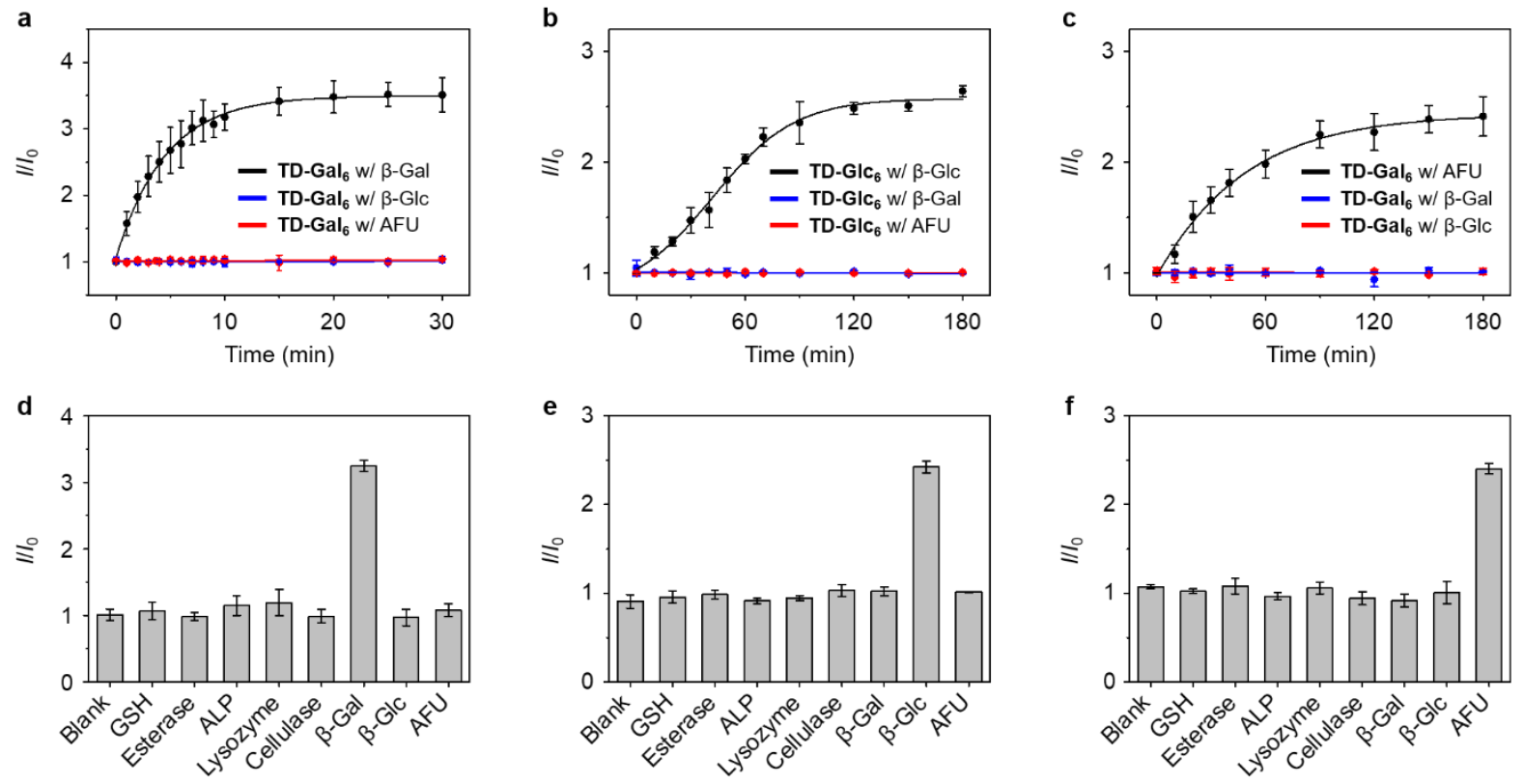

Figure 3. Plotting the fluorescence changes of (a) TD-Gal6 $(10 \mu \mathrm{M})$ with $\beta$-Gal $\left(5 \mathrm{U} \mathrm{mL}^{-1}\right)$ at $\mathrm{pH} 4.0$, (b) TD-Glc6 $(10 \mu \mathrm{M})$ with $\beta$-Glc $\left(5 \mathrm{U} \mathrm{mL}^{-1}\right)$ at $\mathrm{pH} 5.0$, and (c) TD-Fuc6 $(2 \mu \mathrm{M})$ with AFU (0.12 $\left.\mathrm{U} \mathrm{mL}^{-1}\right)$ at $\mathrm{pH} 5.0$ as a function of time. Fluorescence changes of (d) TD-Gal6 (10 $\mu \mathrm{M})$, (e) TD-Glc $6(10 \mu \mathrm{M})$ and (f) TD-Fuc $6(2 \mu \mathrm{M})$ with different analytes including GSH (100 $\mu \mathrm{M})$, esterase $\left(5.0 \mathrm{U} \mathrm{mL}^{-1}\right), \operatorname{ALP}\left(5 \mathrm{U} \mathrm{mL}^{-1}\right)$, lysozyme $\left(5.0 \mathrm{U} \mathrm{mL}^{-1}\right)$, cellulase $\left(5.0 \mathrm{U} \mathrm{mL}^{-1}\right)$, $\beta$ $\operatorname{Gal}\left(5.0 \mathrm{U} \mathrm{mL}^{-1}\right), \beta$-Glc $\left(5.0 \mathrm{U} \mathrm{mL}^{-1}\right)$ and AFU $\left(0.12 \mathrm{U} \mathrm{mL}^{-1}\right) . I$ and $I_{0}$ are the fluorescence intensity of a glycocluster in the presence and absence of an analyte, respectively. All fluorescence spectra were recorded in PBS $(0.01 \mathrm{M}, \mathrm{pH}$ as indicated) with an excitation at 420 $\mathrm{nm}$.

A kinetic study showed that the fluorescence of the hexavalent AIE-based glycoclusters is enhanced in a time-dependent manner in the presence of the specific glycosidase (TD-Gal6 
with $\beta$-Gal (Fig. 3a and S7b), TD-Gle6 with $\beta$-Glc (Fig. 3b) and TD-Fuc6 with AFU (Fig. 3c). In contrast, the long-time incubation of the glycoclusters with non-specific glycosidases (TDGal6 with $\beta$-Glc/AFU (Fig. 3a and S7b), TD-Gle6 with $\beta$-Gal/AFU (Fig. 3b) and TD-Fuc6 with $\beta$-Gal/ $\beta$-Glc (Fig. 3c) did not cause the fluorescence of the probes to increase. Then, a broader range of relevant biomolecules including glutathione (GSH), esterase, alkaline phosphatase (ALP), lysozyme (Lyso) and cellulase (Cel) were used to assess the selectivity of the glycoclusters. To our delight, the glycoclusters showed a fluorescence enhancement only in the presence of their specific glycosidase (TD-Gal6 with $\beta$-Gal (Fig. 3d and S7c), TD-Glc6 with $\beta$-Glc (Fig. 3e) and TD-Fuc 6 with AFU (Fig. 3f)), corroborating the good enzyme specificity of the probes.

Fluorescence imaging of glycosidases in cells with the hexavalent glycoclusters. Having determined the outstanding sensitivity and selectivity of the AIE-based glycoclusters for glycosidases in solution, we turned our attention to the use of these probes for the fluorescence imaging of glycosidases activity in cells. $\beta$-Gal is a secretory protein that is over-expressed during cell senescence ${ }^{65}$ and in human ovarian cancer cells. ${ }^{66}$ The ability to accurately image $\beta$-Gal's activity at the cellular level can help advance glycobiology and offer useful tools for disease diagnosis. Therefore, we examined the cell imaging performances of TD-Gal6 for endogenously produced $\beta$-Gal in Wi38 (fibroblasts derived from lung tissue) and SKOV-3 (human ovarian cancer) cells. We treated Wi38 cells with $\mathrm{H}_{2} \mathrm{O}_{2}$ leading to oxidative stressinduced cell senescence, and thus an overexpression of lysosomal $\beta$-Gal. ${ }^{3}$ For the cell imaging experiment with SKOV-3, HUVEC (human umbilical vein endothelial) cells that hardly express $\beta$-Gal were used as control (Fig. 4). ${ }^{67}$ 


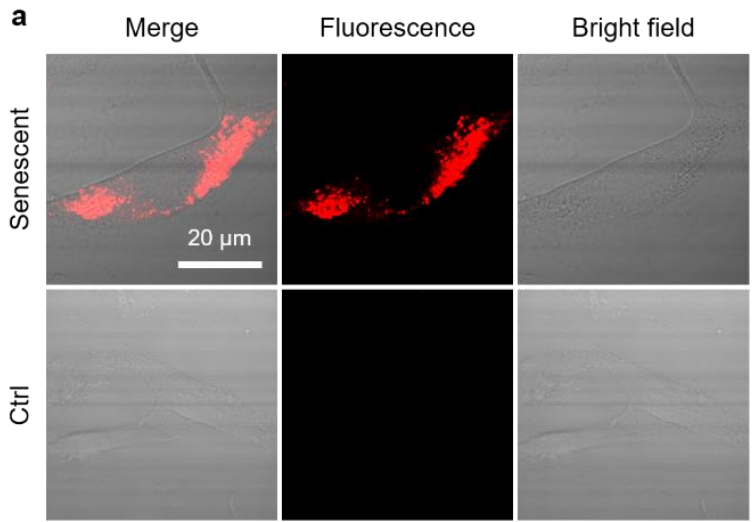

c

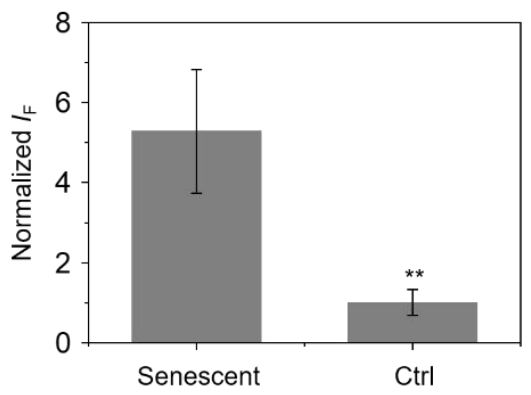

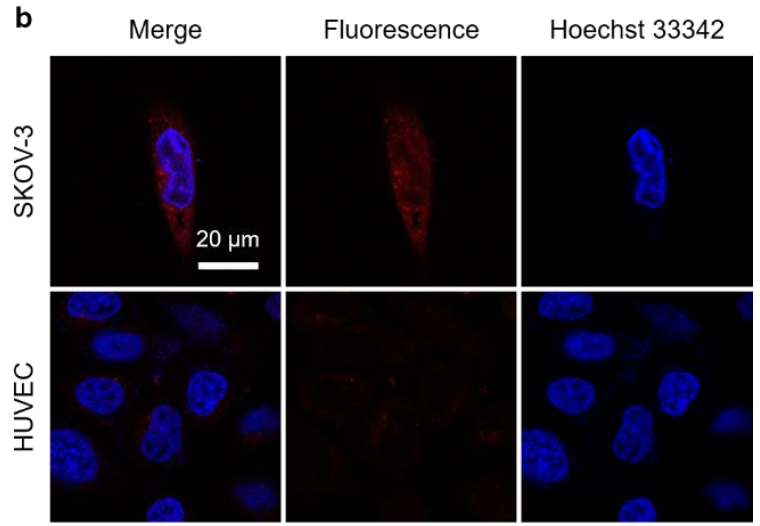

d

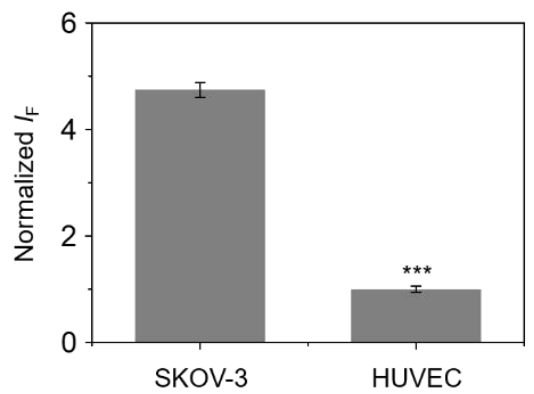

Figure 4. (a) Fluorescence imaging and (b) quantification of Wi-38 cells with (Senescent) and without (Ctrl) after incubation with TD-Gal6 $(10 \mu \mathrm{M})$ for $40 \mathrm{~min}$. (b) Fluorescence imaging and (d) quantification of SKOV-3 (human ovarian carcinoma cells) and HUVEC (human umbilical vein endothelium cells) cells after incubation with TD-Gal6 $(10 \mu \mathrm{M})$ for $40 \mathrm{~min}$. The excitation and emission channels used for TD-Gal6 are $488 \mathrm{~nm}$ and 580-620 nm, respectively; those for Hoechst 33342 are $405 \mathrm{~nm}$ and 440-480 nm, respectively. S. D. means standard deviation $(\mathrm{n}=3)$. $* * P<0.01, * * * P<0.001$.

We determined that the fluorescence intensity of TD-Gal6 was negligible in untreated Wi38 cells (control) due to the absence of intracellular $\beta$-Gal. In contrast, in senescent Wi38 cells treated by $\mathrm{H}_{2} \mathrm{O}_{2}$, an intensive red fluorescence signal corresponding to the degalactosylated AIE dye was observed (Fig. 4a). Similarly, TD-Gal6 produced a strong fluorescence in ovarian cancer cells (SKOV-3 cells, Fig. 4b), but not in HUVEC cells that lack the expression of $\beta$-Gal. A subsequent fluorescence quantification showed a 5.3-fold (Fig. 4c) and 4.7-fold (Fig. 4d) stronger fluorescence emission intensity of the glycocluster in senescent 
and SKOV-3 cells than in untreated Wi38 and HUVEC cells, respectively. A cell viability assay showed that TD-Gal6 did not impact cell proliferation of SKOV-3 even at a concentration of $100 \mu \mathrm{M}$, which is 10-fold higher than that used for cell imaging (Fig. S11). These data suggest the ability of the AIE-based glycocluster for the fluorescence-based imaging of intracellular glycosidase activity.

It is reported that the subcellular localization of endogenous $\beta$-Gal is different between senescent and ovarian cells. While $\beta$-Gal is preferentially localized in the lysosomes in senescent cells, the enzyme was found to be universally distributed in the cytoplasm of ovarian cells such as SKOV-3. ${ }^{67}$ To test whether TD-Gal6 was able to differentiate the subcellular localization of $\beta$-Gal in different cell lines, a co-staining assay was carried out with commercial subcellular trackers including a Lyso-Tracker (for lysosomes), Mito-Tracker (for mitochondria) and Hoechst 33342 (for cell nucleus) (Fig. 5). We first observed that, the red fluorescence of the AIEgen produced by in situ $\beta$-Gal hydrolysis in senescent Wi38 cells overlapped well with the green fluorescence of Lyso-Tracker with a Pearson's coefficient of 0.91 (Fig. 5b). In contrast, a lower Pearson's coefficient of 0.71 was determined by overlapping the AIE fluorescence with that of the Mito-Tracker (Fig. 5b). By co-incubation of the subcellular trackers with TD-Gal6 in SKOV-3 cells, a good fluorescence overlap with both organelles was observed (Fig. 5a). A high Pearson's coefficient of 0.95 and 0.92 was determined for the probe with Lyso-Tracker and Mito-Tracker, respectively. These results prove the effectiveness of AIE-based glycoclusters to precisely localize $\beta$-Gal activity in cells with different pathological states. 

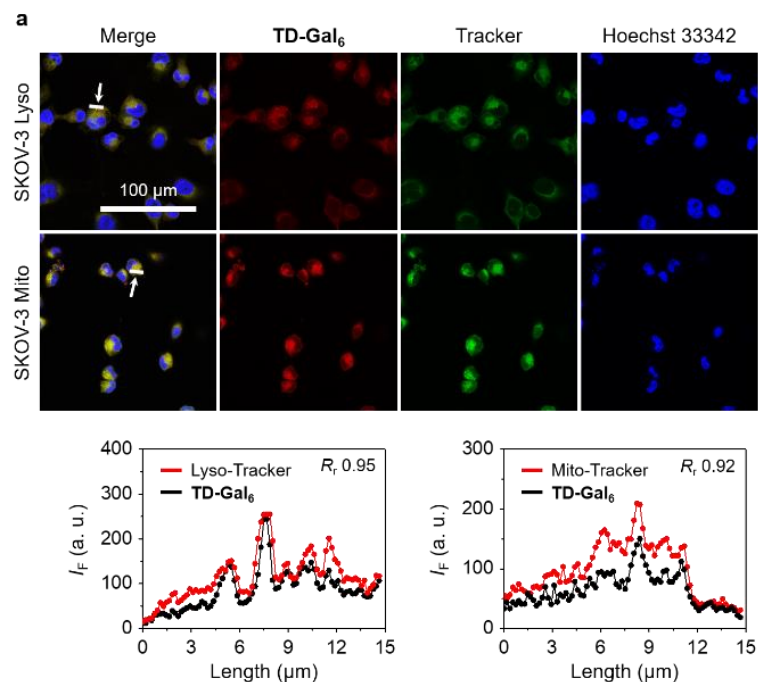
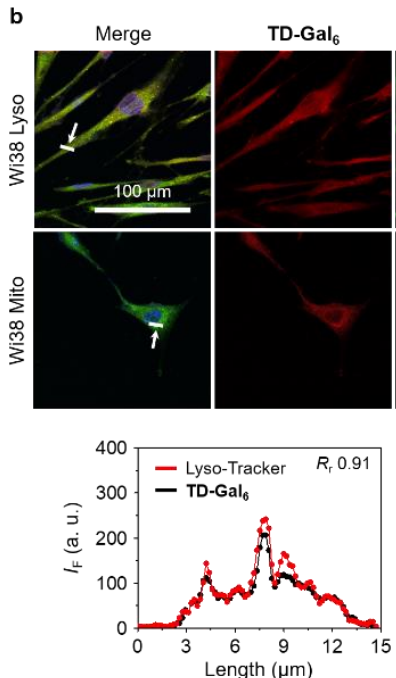

Tracker

Hoechst 33342
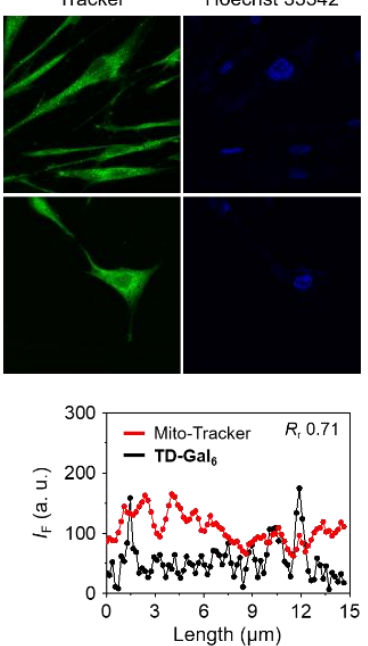

Figure 5. Fluorescence imaging and quantification (the arrow-pointed areas) of (a) senescent Wi-38 (fibroblasts derived from lung tissue) cells and (b) SKOV-3 (human ovarian carcinoma) after incubation with TD-Gal $6(10 \mu \mathrm{M})$ for $4 \mathrm{~h}$. Commercial Mito- and Lyso-tracker were used for fluorescence co-localization with the probe. The excitation and emission channels used for TD-Gal6 are $488 \mathrm{~nm}$ and 580-620 nm, respectively; those for Mito-tracker are $633 \mathrm{~nm}$ and 650-670 nm, respectively; those for Mito-tracker are $633 \mathrm{~nm}$ and 650-670 nm, respectively. $R_{\mathrm{r}}$ means Pearson's coefficient.

To demonstrate the scope of the AIE-based glycocluster for glycosidase sensing at the cellular level, we further used TD-Fuc 6 for probing the endogenous AFU activity in 293T (human embryonic kidneys) cells. ${ }^{68}$ Cells pre-treated with a known AFU inhibitor (1deoxyfuconojirimycin $)^{69}$ were used as control. To our delight, an intensive fluorescence emission corresponding to the residual AIEgen of TD-Fuc 6 after removal of the fucosyl epitopes was observed in the cytoplasm of $293 \mathrm{~T}$ cells (Fig. 6a). However, the fluorescence intensity of the probe decreased gradually with increasing AFU inhibitor $(5 \mu \mathrm{M}$ and $10 \mu \mathrm{M})$ (Fig. 6b). This suggests that the fluorescence production of TD-Fuc 6 in 293T cells is dependent on the intracellular AFU activity. A survey of previous literature reports demonstrates a scarcity in the achievement of fluorescence-based imaging of AFU activity in live cells. This is probably 
owing to the difficulty in the synthesis of fluorogenic $\alpha$-L-fucosyl probes through direct phenol glycosylation. The successful development of TD-Fuc 6 offers a powerful imaging tool for the in-depth study of AFU-relevant biological and pathological processes in different types of mammalian cells.
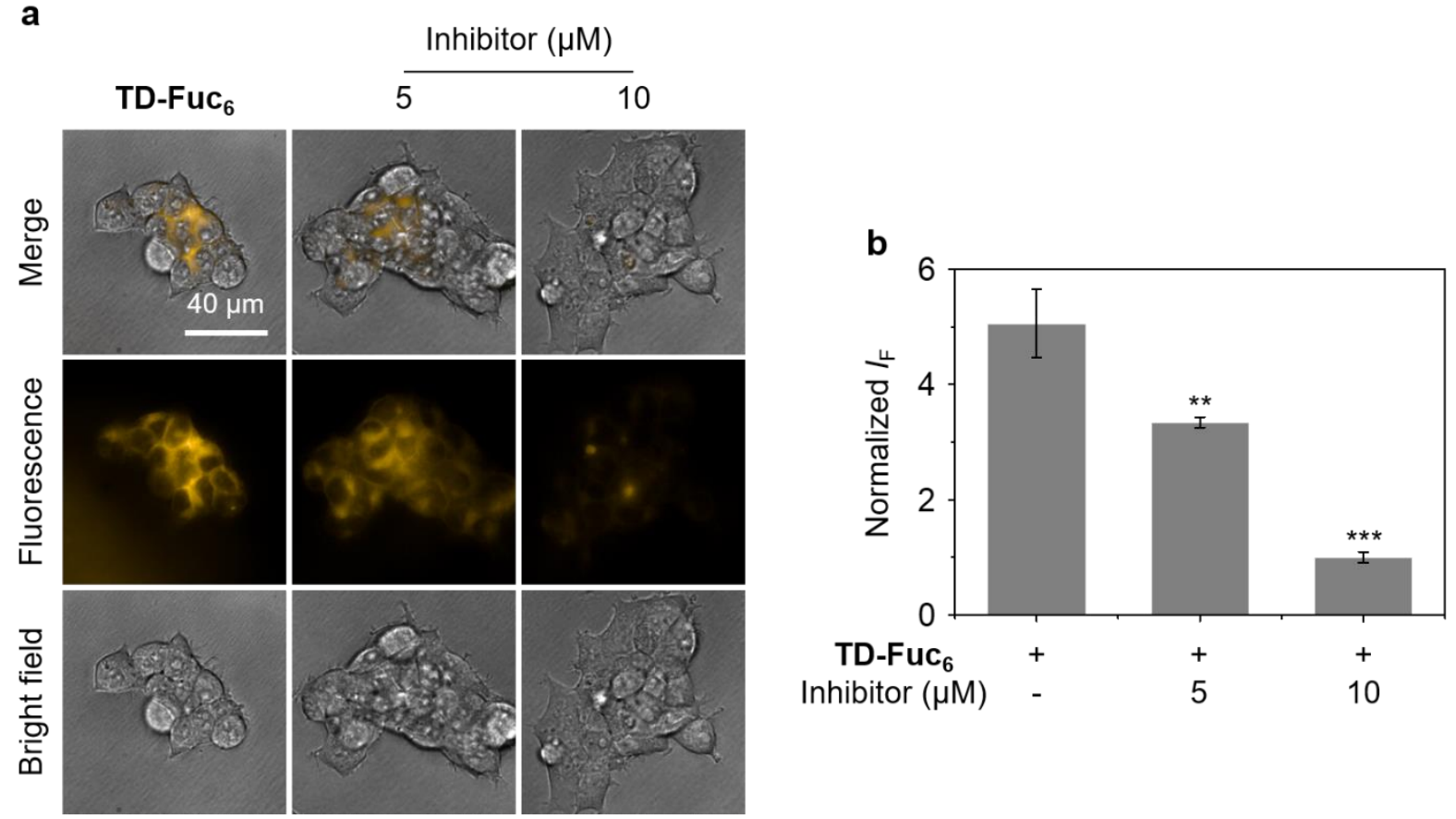

Figure 6. (a) Fluorescence imaging and (b) quantification of 293T (human embryonic kidney cells) cells without and with pre-treatment of a known fucosidase inhibitor (1deoxyfuconojirimycin) after incubation with TD-Fuc6 $(10 \mu \mathrm{M})$ for $40 \mathrm{~min}$. The excitation and emission channels used for TD-Gal6 are $488 \mathrm{~nm}$ and 570-630 nm, respectively. S. D. means standard deviation $(\mathrm{n}=3)$. $* * P<0.01, * * * P<0.001$. 

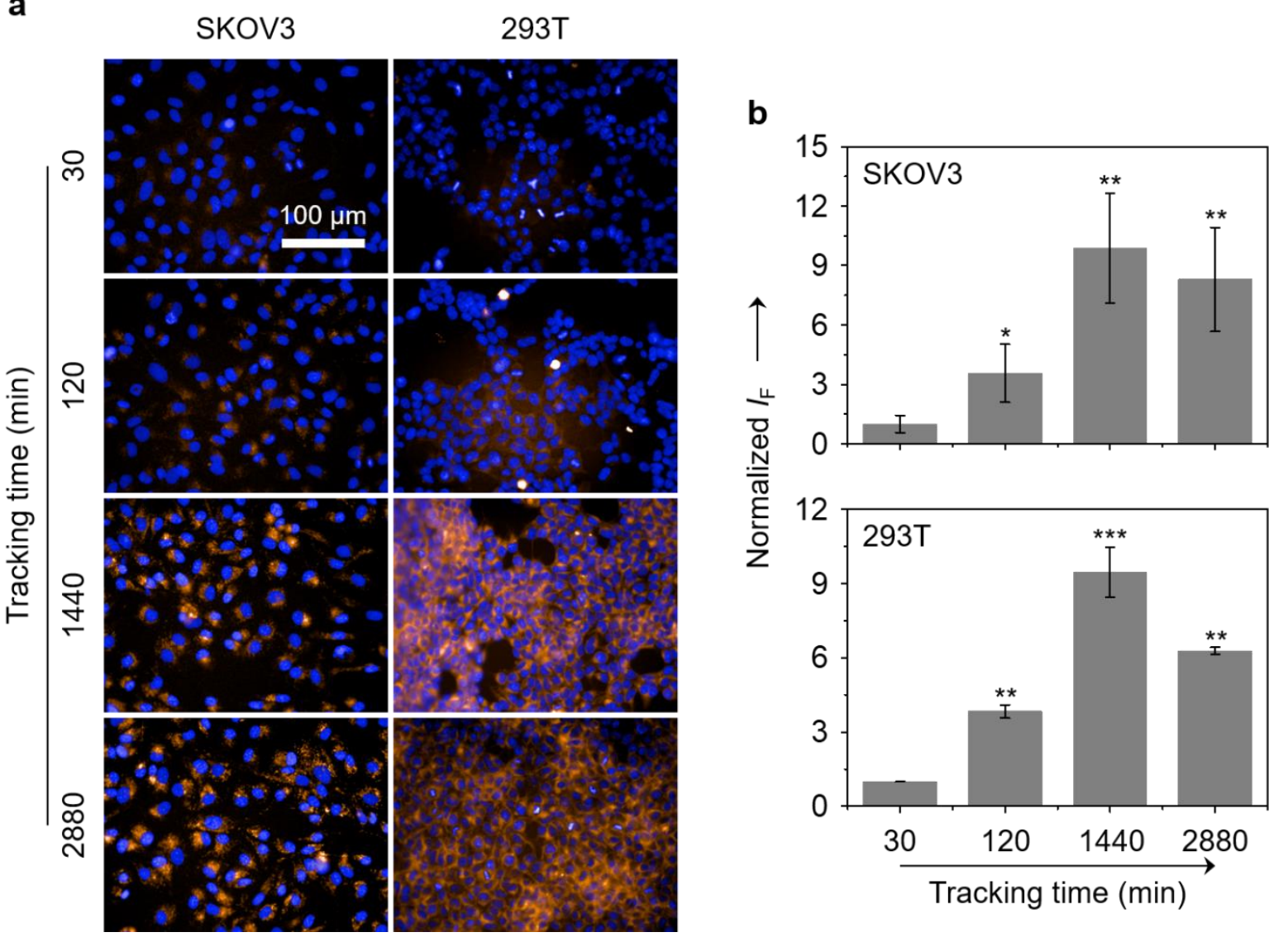

Figure 7. (a) Fluorescence imaging and (b) quantification of SKOV-3 (human ovarian carcinoma cells) and 293T (human embryonic kidney cells) cells after incubation with TD-Gal6 $(10 \mu \mathrm{M})$ and TD-Fuc6 $(10 \mu \mathrm{M})$, respectively, with time. The excitation and emission channels used for TD-Gal/6/TD-Fuc6 are $488 \mathrm{~nm}$ and 580-620 nm, respectively; those for Hoechst 33342 are $405 \mathrm{~nm}$ and 440-480 nm, respectively. S. D. means standard deviation $(\mathrm{n}=3)$. $* * P<0.01, * * * P<0.001$.

Large-sized aggregates and particles were shown to have a slower exocytotic rate than dispersed small molecules due to a prolonged intracellular retention thanks to the size effect. ${ }^{36}$, ${ }^{70-71}$ Given the AIE feature of the glycoclusters, we also tested their cell imaging capacity with time (Fig. 7). After treating SKOV-3 cells with TD-Gal6 for $30 \mathrm{~min}$, a relatively weak fluorescence signal was observed probably due to the insufficient de-glycosylation of the glycoclusters intracellularly. This fluorescence was then enhanced when the incubation time 
was increased to $120 \mathrm{~min}$, suggesting an increase in the proportion of de-glycosylated AIEgens. After a further prolonged incubation time of $1440 \mathrm{~min}(24 \mathrm{~h})$, a $c a$. 9.9-fold increase in fluorescence intensity was observed with respect to the group with the incubation time of 30 min. Finally, the fluorescence was slightly reduced when the incubation time was increased to $2880 \mathrm{~min}(48 \mathrm{~h})$. Likewise, a similar trend in fluorescence change was observed for TD-Fuc6 in 293T cells over time. The fluorescence of the probe maximized in $1440 \mathrm{~min}$ with a $c a .9 .5-$ fold increase in fluorescence intensity with respect to the initial 30 min group, and then slightly decreased with a further prolonged incubation time of $2880 \mathrm{~min}$. These data suggest that our glycosidase-responsive AIE-based glycoclusters are amenable to (1) monitoring the kinetics of enzymatic activity intracellularly, and (2) imaging of cells for more than 48 hours because of a slow exocytosis rate of the de-glycosylated AIEgen aggregates. The first point is particularly useful for the interrogation of the de-glycosylation process of a glycosidase of interest that is overly expressed during a given cellular process.

\section{CONCLUSIONS}

In summary, to overcome the synthetic limitations associated with previously reported fluorogenic glycosidase probes, we have developed AIE-based glycoclusters with excellent sensitivity and selectivity as a platform strategy for sensing the activity of diverse glycosidases in solution and in cells. A comparison of the sensing performances among four series of structurally different glycoclusters identified hexavalent TPE-DCM-based glycoclusters as the optimal structural motif for glycosidase sensing through AIE. The synthetic strategy avoids the direct glycosylation on phenol group of D-A-type fluorogens, leading to the acquisition of 
structurally more diverse glycosidase substrates based on the simple and efficient click coupling between an alkynylated TPE-DCM core and azido glycosides. Upon enzymatic hydrolysis of the glycosyl epitopes, the resultant amphiphilic AIEgens aggregated in water to form micelles, thereby producing a drastically enhanced, stable fluorescence signal.

The AIE-based glycoclusters achieved (1) the fluorogenic detection of different glycosidases including galactosidase, glucosidase and fucosidase with excellent selectivity over a number of other enzymes that exist in the human body, (2) fluorescence-based imaging of the endogenous glycosidase activity in different cell types through intracellular deglycosylation producing aggregated AIEgens, (3) differentiation of the subcellular localization of a galactosidase between cancer and senescent cells, and (4) study of the kinetics of the deglycosylation action of different glycosidases, and the subsequent long-term fluorescent imaging of cells thanks to the slow exocytosis of AIEgen aggregates. Our research addresses the scarcity in universal functional imaging tools for glycosidases, in particular fucosidases that have been identified to be useful cancer biomarkers. ${ }^{72}$

\section{Notes}

The authors declare no competing financial interest.

\section{ACKNOWLEDGMENTS}

S.V. thank the Universite Claude Bernard Lyon 1 and the CNRS for financial support. The authors at ECUST are grateful to the financial support from the Natural Science Foundation of China (nos. 21788102 and 91853201), the Shanghai Municipal Science and Technology Major 
Project (No. 2018SHZDZX03) and the Fundamental Research Funds for the Central Universities (222201717003). L.D. thanks the China Scholarship Council for a PhD stipend (No. 201606740066). H.-H.H. would like to thank the Project funded by China Postdoctoral Science Foundation (No. 2020M681196).

\section{REFERENCES}

1. Weignerová, L.; Bojarová, P.; Křen, V., Glycosidases in synthesis. In Carbohydrate Chemistry, Rauter, A. P., Lindhorst, T. K., 2009; pp 311-333.

2. Lee, B. Y.; Han, J. A.; Im, J. S.; Morrone, A.; Johung, K.; Goodwin, E. C.; Kleijer, W. J.; DiMaio, D.; Hwang, E. S., Senescence-associated $\beta$-galactosidase is lysosomal $\beta$ galactosidase. Aging Cell 2006, 5, 187-195.

3. Dimri, G. P.; Lee, X.; Basile, G.; Acosta, M.; Scott, G.; Roskelley, C.; Medrano, E. E.; LINskENs, M.; Rubelj, I.; Pereira-Smith, O., A biomarker that identifies senescent human cells in culture and in aging skin in vivo. Proc. Natl Acad. Sci. U.S.A. 1995, 92, 9363-9367.

4. Spergel, D. J.; Krüth, U.; Shimshek, D. R.; Sprengel, R.; Seeburg, P. H., Using reporter genes to label selected neuronal populations in transgenic mice for gene promoter, anatomical, and physiological studies. Progr. Neurobiol. 2001, 63, 673-686.

5. Winchester, B. G., Lysosomal metabolism of glycoconjugates. In Biology of the Lysosome, Lloyd, J. B.; Mason, R.W., Springer: 1996; pp 191-238.

6. Becker, D. J.; Lowe, J. B., Fucose: biosynthesis and biological function in mammals. Glycobiology 2003, 13, 41R-53R.

7. Abdel-Aleem, H.; Ahmed, A.; Sabra, A.; Zakhari, M.; Soliman, M.; Hamed, H., Serum $\alpha-$ L-fucosidase enzyme activity in ovarian and other female genital tract tumors. Int. J. Gynecol. Obst. 1996, 55, 273-279.

8. Waidely, E.; Al-Yuobi, A.-R. O.; Bashammakh, A.; El-Shahawi, M. S.; Leblanc, R. M., Serum protein biomarkers relevant to hepatocellular carcinoma and their detection. Analyst 2016, 141, 36-44.

9. Safir Filho, M.; Dao, P.; Gesson, M.; Martin, A. R.; Benhida, R., Development of highly sensitive fluorescent probes for the detection of $\beta$-galactosidase activity - application to the real-time monitoring of senescence in live cells. Analyst 2018, 143, 2680-2688.

10. Calatrava-Perez, E.; Bright, S. A.; Achermann, S.; Moylan, C.; Senge, M. O.; Veale, E. B.; Williams, D. C.; Gunnlaugsson, T.; Scanlan, E. M., Glycosidase activated release of fluorescent 1,8-naphthalimide probes for tumor cell imaging from glycosylated 'pro-probes'. Chem. Commun. 2016, 52, 13086-13089. 
11. Hyun, J. Y.; Kang, N. R.; Shin, I., Carbohydrate Microarrays Containing Glycosylated Fluorescent Probes for Assessment of Glycosidase Activities. Org. Lett. 2018, 20, 1240-1243. 12. Hou, X.; Peng, J.; Zeng, F.; Yu, C.; Wu, S., An anthracenecarboximide fluorescent probe for in vitro and in vivo ratiometric imaging of endogenous $\alpha$-L-fucosidase for hepatocellular carcinoma diagnosis. Mater. Chem. Front. 2017, 1, 660-667.

13. Hsu, Y. L.; Nandakumar, M.; Lai, H. Y.; Chou, T. C.; Chu, C. Y.; Lin, C. H.; Lo, L. C., Development of Activity-Based Probes for Imaging Human $\alpha$-L-Fucosidases in Cells. J. Org. Chem. 2015, 80, 8458-8463.

14. Thomas, B.; Yan, K. C.; Hu, X. L.; Donnier-Maréchal, M.; Chen, G. R.; He, X. P.; Vidal, S., Fluorescent glycoconjugates and their applications. Chem. Soc. Rev. 2020, 49, 593-641.

15. Li, X.; Pan, Y.; Chen, H.; Duan, Y.; Zhou, S.; Wu, W.; Wang, S.; Liu, B., Specific NearInfrared Probe for Ultrafast Imaging of Lysosomal $\beta$-Galactosidase in Ovarian Cancer Cells. Anal. Chem. 2020, 92, 5772-5779.

16. Zhang, Y.; Yan, C.; Wang, C.; Guo, Z.; Liu, X.; Zhu, W. H., A Sequential Dual-Lock Strategy for Photoactivatable Chemiluminescent Probes Enabling Bright Duplex Optical Imaging. Angew. Chem. Int. Ed. 2020, 59, 9059-9066.

17. Jiang, G.; Zeng, G.; Zhu, W.; Li, Y.; Dong, X.; Zhang, G.; Fan, X.; Wang, J.; Wu, Y.; Tang, B. Z., A selective and light-up fluorescent probe for beta-galactosidase activity detection and imaging in living cells based on an AIE tetraphenylethylene derivative. Chem. Commun. 2017, 53, 4505-4508.

18. Zhang, X. X.; Wu, H.; Li, P.; Qu, Z. J.; Tan, M. Q.; Han, K. L., A versatile two-photon fluorescent probe for ratiometric imaging $E$. coli $\beta$-galactosidase in live cells and in vivo. Chem. Commun. 2016, 52, 8283-8286.

19. Burke, H. M.; Gunnlaugsson, T.; Scanlan, E. M., Recent advances in the development of synthetic chemical probes for glycosidase enzymes. Chem. Commun. 2015, 51, 10576-10588. 20. Cheng, X.; Huang, Y.; Li, D.; Yuan, C.; Li, Z.-L.; Sun, L.; Jiang, H.; Ma, J., A sensitive polymer dots fluorescent sensor for determination of $\alpha$-L-fucosidase activity in human serum. Sensors and Actuators B: Chemical 2019, 288, 38-43.

21. Zhao, M.; Qian, Z.; Zhong, M.; Chen, Z.; Ao, H.; Feng, H., Fabrication of Stable and Luminescent Copper Nanocluster-Based AIE Particles and Their Application in $\beta$ Galactosidase Activity Assay. ACS Appl. Mater. Interfaces 2017, 9, 32887-32895.

22. Liu, H. W.; Chen, L.; Xu, C.; Li, Z.; Zhang, H.; Zhang, X. B.; Tan, W., Recent progresses in small-molecule enzymatic fluorescent probes for cancer imaging. Chem. Soc. Rev. 2018, 47, 7140-7180.

23. Lee, H. W.; Heo, C. H.; Sen, D.; Byun, H. O.; Kwak, I. H.; Yoon, G.; Kim, H. M., Ratiometric two-photon fluorescent probe for quantitative detection of $\beta$-galactosidase activity in senescent cells. Anal. Chem. 2014, 86, 10001-10005. 
24. Zhang, J.; Li, C.; Dutta, C.; Fang, M.; Zhang, S.; Tiwari, A.; Werner, T.; Luo, F. T.; Liu, H., A novel near-infrared fluorescent probe for sensitive detection of $\beta$-galactosidase in living cells. Anal. Chim. Acta 2017, 968, 97-104.

25. Kim, E. J.; Kumar, R.; Sharma, A.; Yoon, B.; Kim, H. M.; Lee, H.; Hong, K. S.; Kim, J. S., In vivo imaging of beta-galactosidase stimulated activity in hepatocellular carcinoma using ligand-targeted fluorescent probe. Biomaterials 2017, 122, 83-90.

26. Gu, K.; Qiu, W.; Guo, Z.; Yan, C.; Zhu, S.; Yao, D.; Shi, P.; Tian, H.; Zhu, W. H., An enzyme-activatable probe liberating AIEgens: on-site sensing and long-term tracking of $\beta$ galactosidase in ovarian cancer cells. Chem. Sci. 2019, 10, 398-405.

27. Li, X.; Qiu, W.; Li, J.; Chen, X.; Hu, Y.; Gao, Y.; Shi, D.; Li, X.; Lin, H.; Hu, Z.; Dong, G.; Sheng, C.; Jiang, B.; Xia, C.; Kim, C.-Y.; Guo, Y.; Li, J., First-generation species-selective chemical probes for fluorescence imaging of human senescence-associated $\beta$-galactosidase. Chem. Sci. 2020, 11, 7292-7301.

28. Gu, K.; Xu, Y.; Li, H.; Guo, Z.; Zhu, S.; Zhu, S.; Shi, P.; James, T. D.; Tian, H.; Zhu, W. H., Real-Time Tracking and In Vivo Visualization of $\beta$-Galactosidase Activity in Colorectal Tumor with a Ratiometric Near-Infrared Fluorescent Probe. J. Am. Chem. Soc. 2016, 138, 5334-5340.

29. Luo, J.; Xie, Z.; Lam, J. W.; Cheng, L.; Chen, H.; Qiu, C.; Kwok, H. S.; Zhan, X.; Liu, Y.; Zhu, D.; Tang, B. Z., Aggregation-induced emission of 1-methyl-1,2,3,4,5-pentaphenylsilole. Chem. Commun. 2001, 1740-1741.

30. Hong, Y.; Lam, J. W.; Tang, B. Z., Aggregation-induced emission. Chem. Soc. Rev. 2011, 40, 5361-5388.

31. Ding, D.; Li, K.; Liu, B.; Tang, B. Z., Bioprobes based on AIE fluorogens. Acc. Chem. Res. 2013, 46, 2441-2453.

32. Mei, J.; Leung, N. L.; Kwok, R. T.; Lam, J. W.; Tang, B. Z., Aggregation-Induced Emission: Together We Shine, United We Soar! Chem. Rev. 2015, 115, 11718-11940.

33. Guo, Z.; Shao, A.; Zhu, W.-H., Long wavelength AIEgen of quinoline-malononitrile. J. Mater. Chem. C 2016, 4, 2640-2646.

34. Wang, X.; Gao, Z.; Zhu, J.; Gao, Z.; Wang, F., Aggregation induced emission of a cyanostilbene amphiphile as a novel platform for FRET-based ratiometric sensing of mercury ions in water. Polym. Chem. 2016, 7, 5217-5220.

35. Wang, J. X.; Chen, Q.; Bian, N.; Yang, F.; Sun, J.; Qi, A. D.; Yan, C. G.; Han, B. H., Sugar-bearing tetraphenylethylene: novel fluorescent probe for studies of carbohydrate-protein interaction based on aggregation-induced emission. Org. Biomol. Chem. 2011, 9, 2219-2226.

36. Panyam, J.; Labhasetwar, V., Dynamics of Endocytosis and Exocytosis of Poly(D,LLactide-co-Glycolide) Nanoparticles in Vascular Smooth Muscle Cells. Pharm. Res. 2003, 20, 212-220. 
37. Jin, H.; Heller, D. A.; Sharma, R.; Strano, M. S., Size-Dependent Cellular Uptake and Expulsion of Single-Walled Carbon Nanotubes: Single Particle Tracking and a Generic Uptake Model for Nanoparticles. ACS Nano 2009, 3, 149-158.

38. Zhang, J.; Cheng, P.; Pu, K., Recent Advances of Molecular Optical Probes in Imaging of beta-Galactosidase. Bioconjugate Chem. 2019, 30, 2089-2101.

39. Wadzinski, T. J.; Steinauer, A.; Hie, L.; Pelletier, G.; Schepartz, A.; Miller, S. J., Rapid phenolic $O$-glycosylation of small molecules and complex unprotected peptides in aqueous solvent. Nat. Chem. 2018, 10, 644-652.

40. Jensen, K. J., O-Glycosylations under neutral or basic conditions. J. Chem. Soc., Perkin Trans. 1 2002, 2219-2233.

41. Jacobsson, M.; Malmberg, J.; Ellervik, U., Aromatic O-glycosylation. Carbohydr. Res. 2006, 341, 1266-1281.

42. Qiu, X.; Fairbanks, A. J., Scope of the DMC mediated glycosylation of unprotected sugars with phenols in aqueous solution. Org. Biomol. Chem. 2020, 18, 7355-7365.

43. Li, K. B.; Wei, X. L.; Zang, Y.; He, X. P.; Chen, G. R.; Li, J.; Chen, K., Revisit of a dipropargyl rhodamine probe reveals its alternative ion sensitivity in both a solution and live cells. Analyst 2013, 138, 7087-7089.

44. (a) Stick, R. V.; Williams, S. J., The Reactions of Monosaccharides. In Carbohydrates: The Essential Molecules of Life (Second Edition), Stick, R. V.; Williams, S. J., Eds. Elsevier: Oxford, 2009; pp 75-131. (b) Namchuk, M. N.; McCarter, J. D.; Becalski, A.; Andrews, T.; Withers, S. G., The Role of Sugar Substituents in Glycoside Hydrolysis. J. Am. Chem. Soc. 2000, 122, 1270-1277.

45. Capon, B., Mechanism in carbohydrate chemistry. Chem. Rev. 1969, 69, 407-498.

46. Dong, L.; Chen, G. R.; He, X. P.; Vidal, S., Thiophenol detection using an AIE fluorescent probe through self-assembly with TPE-based glycoclusters. Org. Biomol. Chem. 2019, 17, 9251-9256.

47. Dong, L.; Fu, M.; Liu, L.; Han, H.-H.; Zang, Y.; Chen, G.-R.; Li, J.; He, X.-P.; Vidal, S., Supramolecular Assembly of TPE-Based Glycoclusters with Dicyanomethylene-4H-pyran (DM) Fluorescent Probes Improve Their Properties for Peroxynitrite Sensing and Cell Imaging. Chem. Eur. J. 2020, 26, 14445-14452.

48. Cai, X.; Zhang, C.-J.; Ting Wei Lim, F.; Chan, S. J.; Bandla, A.; Chuan, C. K.; Hu, F.; Xu, S.; Thakor, N. V.; Liao, L.-D.; Liu, B., Organic Nanoparticles with Aggregation-Induced Emission for Bone Marrow Stromal Cell Tracking in a Rat PTI Model. Small 2016, 12, 65766585 .

49. Chen, Z.; Hu, W.; Wang, M.; Wang, L.; Su, G.; Wang, J., Synthesis and evaluation of a water-solubility glycosyl-rhodamine fluorescent probe detecting $\mathrm{Hg}^{2+}$. Carbohydr. Res. 2016, $429,81-86$. 
50. Rao, M.; Kanagaraj, K.; Fan, C.; Ji, J.; Xiao, C.; Wei, X.; Wu, W.; Yang, C., Photocatalytic Supramolecular Enantiodifferentiating Dimerization of 2-Anthracenecarboxylic Acid through Triplet-Triplet Annihilation. Org. Lett. 2018, 20, 1680-1683.

51. Zhao, G.; Zhu, Y.; Guang, S.; Ke, F.; Xu, H., Facile preparation and investigation of the properties of single molecular POSS-based white-light-emitting hybrid materials using click chemistry. New J. Chem. 2018, 42, 555-563.

52. Dong, L.; Peng, H.-Q.; Niu, L.-Y.; Yang, Q.-Z., Modulation of Aggregation-Induced Emission by Excitation Energy Transfer: Design and Application. Top. Curr. Chem. 2021, 379 (3), https://doi.org/10.1007/s41061-021-00330-0.

53. Craven, G. R.; Steers, E.; Anfinsen, C. B., Purification, Composition, and Molecular Weight of the $\beta$-Galactosidase of Escherichia coli K12. J. Biol. Chem. 1965, 240, 2468-2477. 54. Tiwari, V. K.; Mishra, B. B.; Mishra, K. B.; Mishra, N.; Singh, A. S.; Chen, X., CuCatalyzed Click Reaction in Carbohydrate Chemistry. Chem. Rev. 2016, 116, 3086-3240.

55. He, X.-P.; Zeng, Y.-L.; Zang, Y.; Li, J.; Field, R. A.; Chen, G.-R., Carbohydrate CuAAC click chemistry for therapy and diagnosis. Carbohydr. Res. 2016, 429, 1-22.

56. Meldal, M.; Tornøe, C. W., Cu-Catalyzed Azide-Alkyne Cycloaddition. Chem. Rev. 2008, 108, 2952-3015.

57. Rosselin, M.; Chinoy, Z. S.; Bravo-Anaya, L. M.; Lecommandoux, S.; Garanger, E., Multivalent Elastin-Like Glycopolypeptides: Subtle Chemical Structure Modifications with High Impact on Lectin Binding Affinity. ACS Macro Lett. 2021, 10, 65-70.

58. Cecioni, S.; Almant, M.; Praly, J.-P.; Vidal, S., Synthesis of Azido-Functionalized Carbohydrates for the Design of Glycoconjugates. In Carbohydrate Chemistry: Proven Synthetic Methods, Kováč, P., Ed. CRC Press: Boca Raton, 2012; Vol. 1, pp 175-180.

59. Donnier-Maréchal, M.; Abdullayev, S.; Bauduin, M.; Pascal, Y.; Fu, M. Q.; He, X. P.; Gillon, E.; Imberty, A.; Kipnis, E.; Dessein, R.; Vidal, S., Tetraphenylethylene-based glycoclusters with aggregation-induced emission (AIE) properties as high-affinity ligands of bacterial lectins. Org. Biomol. Chem. 2018, 16, 8804-8809.

60. Bouillon, C.; Meyer, A.; Vidal, S.; Jochum, A.; Chevolot, Y.; Cloarec, J.-P.; Praly, J.-P.; Vasseur, J.-J.; Morvan, F., Microwave Assisted "Click" Chemistry for the Synthesis of Multiple Labeled-Carbohydrate Oligonucleotides on Solid Support. J. Org. Chem. 2006, 71, 4700-4702.

61. Cecioni, S.; Lalor, R.; Blanchard, B.; Praly, J.-P.; Imberty, A.; Matthews, S. E.; Vidal, S., Achieving High Affinity towards a Bacterial Lectin through Multivalent Topological Isomers of Calix[4]arene Glycoconjugates. Chem. Eur. J. 2009, 15, 13232-13240.

62. Gao, Y.; Hu, Y.; Liu, Q.; Li, X.; Li, X.; Kim, C.-Y.; James, T. D.; Li, J.; Chen, X.; Guo, Y., Two-Dimensional Design Strategy to Construct Smart Fluorescent Probes for the Precise Tracking of Senescence. Angew. Chem. Int. Ed. 2021, 60, 10756-10765. 
63. Bailey, M. J.; Linko, M., Production of $\beta$-galactosidase by Aspergillus oryzae in submerged bioreactor cultivation. J. Biotechnol. 1990, 16, 57-66.

64. Li, Y.; Wang, H.; Li, J.; Zheng, J.; Xu, X.; Yang, R., Simultaneous intracellular $\beta$-Dglucosidase and phosphodiesterase I activities measurements based on a triple-signaling fluorescent probe. Anal. Chem. 2011, 83, 1268-1274.

65. Lee, H. W.; Heo, C. H.; Sen, D.; Byun, H.-O.; Kwak, I. H.; Yoon, G.; Kim, H. M., Ratiometric Two-Photon Fluorescent Probe for Quantitative Detection of $\beta$-Galactosidase Activity in Senescent Cells. Anal. Chem. 2014, 86, 10001-10005.

66. Asanuma, D.; Sakabe, M.; Kamiya, M.; Yamamoto, K.; Hiratake, J.; Ogawa, M.; Kosaka, N.; Choyke, P. L.; Nagano, T.; Kobayashi, H.; Urano, Y., Sensitive $\beta$-galactosidase-targeting fluorescence probe for visualizing small peritoneal metastatic tumours in vivo. Nat. Commun. 2015, 6, 6463 .

67. Chai, X.; Han, H.-H.; Sedgwick, A. C.; Li, N.; Zang, Y.; James, T. D.; Zhang, J.; Hu, X.L.; Yu, Y.; Li, Y.; Wang, Y.; Li, J.; He, X.-P.; Tian, H., Photochromic Fluorescent Probe Strategy for the Super-resolution Imaging of Biologically Important Biomarkers. J. Am. Chem. Soc. 2020, 142, 18005-18013.

68. Miura, K.; Tsukagoshi, T.; Hirano, T.; Nishio, T.; Hakamata, W., Development of Fluorogenic Substrates of $\alpha$-L-Fucosidase Useful for Inhibitor Screening and Gene-expression Profiling. ACS Med. Chem. Lett. 2019, 10, 1309-1313.

69. Haijun, W.; Yin, S.; Lei, Z.; Youfan, Y., 1-Deoxynojirimycin and its Derivatives: A Mini Review of the Literature. Curr. Med. Chem. 2021, 28, 628-643.

70. Zhou, L.; Lv, F.; Liu, L.; Shen, G.; Yan, X.; Bazan, G. C.; Wang, S., Cross-Linking of Thiolated Paclitaxel-Oligo(p-phenylene vinylene) Conjugates Aggregates inside Tumor Cells Leads to "Chemical Locks" That Increase Drug Efficacy. Adv. Mater. 2018, 30, 1704888.

71. Wehrman, T. S.; von Degenfeld, G.; Krutzik, P. O.; Nolan, G. P.; Blau, H. M., Luminescent imaging of $\beta$-galactosidase activity in living subjects using sequential reporterenzyme luminescence. Nat. Methods 2006, 3, 295-301.

72. Waidely, E.; Al-Yuobi, A.-R. O.; Bashammakh, A. S.; El-Shahawi, M. S.; Leblanc, R. M., Serum protein biomarkers relevant to hepatocellular carcinoma and their detection. Analyst 2016, 141, 36-44. 